\title{
Heat training in the box turtle (Terrapene carolina)
}

\author{
LEONARD BROSGOLE \\ St. John's University, Jamaica, New York 11499
}

\begin{abstract}
A box turtle was trained on a black-white discrimination task, using escape from heat as a reinforcer. Original learning was followed by five successive cue reversals. It was surprising that the animal's performance did not deteriorate with the first reversal and a learning set failed to develop over the remaining four reversals. The data on this animal were compared to those obtained on gerbils in an earlier study.
\end{abstract}

The purpose of this paper is to present the interested reader with a method for rapidly shaping the box turtle in a color discrimination task. Admittedly, such research is of limited value at present, because the health restrictions placed upon the red-eared slider (Pseudemys scripta elegans) have seriously affected the availability of the box turtle. For this reason, the following data were obtained on an $\mathrm{N}$ of one only. The importance of this research, however, is based upon the development of a unique apparatus, one which was designed to take into account the peculiar response characteristics of the animal. The device employed escape from heat as a means of reinforcement. Thus, the problematic use of a food reinforcer was avoided.

\section{METHOD}

\section{General}

The plan was a simple one. The animal was to be placed into a box consisting of three regions, a startbox, positive goal, and negative goal. A wall divided the start region from the goalboxes. There were two openings in the wall, one to the right and the other to the left, which permitted access to the goalboxes. Half the wall was black and the other half white. White always corresponded to the positive goal, and its position, right or left, was varied from trial to trial. The floors of the box, consisting of $1 / 8$-in.-thick aluminum plate, were heated from below. The heat in the start was sufficient to initiate escape behavior. The floor of the positive goal was insulated, so as to be at room temperature. The negative goal was even hotter than the start, so as to generate an avoidance response. Thus, escape from heat was used to shape a black-white discrimination.

There were some interesting observations on a pilot animal. When placed in the start, the animal would withdraw into its shell and remain there for approximately $30 \mathrm{sec}$. At that point, it would burst forth and head in the general direction of one of the doors. It often came into contact with the dividing wall. The resulting pressure of the shell against the wall caused the animal to rotate, and it again headed in a straight line until contacting another wall. This behavior persisted until the animal became inescapably wedged into a corner of the startbox, where it continued to push in a forward direction. The assistance of the experimenter was then required. The task seemed hopeless, as the turtle apparently was incapable of performing a discrimination in a situation which was previously used with mice and rats (Brosgole, Sobrian, \& Contino, 1972), as well as with gerbils (Brosgole \& Ulatowski, 1973). It was noted that as the trials progressed, however, the animal oriented toward the correct color more often than not-only to become confused by its stereotyped mode of responding. The problem then emerged as to how to permit this apparent species-specific response to work in favor of the animal. This led to modifications in the device, noted below.

\section{Subject}

The experimental animal was a male box turtle of undetermined age. Its carapace was approximately 6 in. in diam. It was on an ad-lib diet of lettuce and water, with meal worms introduced occasionally. It was housed in a well-lit terrarium, containing a bed of gravel, at a constant temperature of $78^{\circ} \mathrm{F}$.

\section{Apparatus}

The device was a box constructed from $1 \times 12$ in. pine. The interior was $16^{1 / 4}$ in. wide $\times 11 \frac{1 / 2}{2}$ in. long. The two adjoining goalboxes were left completely open, no longer separated from the start by a dividing wall. One goal was to the left and the other to the right. The goals were separated by a wall of $1 / 4$-in-thick plywood. Thus, the goals were 8 in. wide $\times 8 \frac{1}{2}$ in. long. A curved wall was inserted into the startbox. The wall was semi-circular, curving along the back and sides of the box and feeding into the goals. It was made of $1 / 4$-in.-thick Masonite that was soaked and pressed into shape. One half was painted a gloss white and the other half a gloss black. The vertical dividing line between the white and black halves was directly aligned with the panel that separated the goals. The position of the colors within the start was changed by simply removing the wall, turning it upside down, and reinserting it. Thus, a trial was initiated by placing the turtle in the start facing the dividing line of the rear wall. The turtle was able to orient toward the color of its choice and head directly into the wall. Because of the curvature of the wall, the animal rotated as it pushed forward until sliding into the appropriate goalbox.

The floors of all compartments were made of aluminum plate. They were heated from below with nichrome wire that was powered by variable, regulated ac supplies. The startbox was heated to $56^{\circ} \mathrm{C}$ and both goals were set at $70^{\circ} \mathrm{C}$. The positive goal was reduced to room temperature, however, by the insertion of an insulating pad made of Masonite and coated with aluminum paint. The surface temperature of the plates was monitored with a Yellow Springs tele-thermometer.

\section{Procedure}

The animal was run for 12 trials a day. A trial consisted of placing the animal in the start position and then detaining it in the goalbox of its choice for $10 \mathrm{sec}$. White was positive and black negative. The position of the colors (right or left) was changed from trial to trial according to the Fellows' series (1967). The animal was run 5 days a week, with a different series used each day. The training continued until the animal made 1.0 of 12 cor- 
rect responses, i.e., reached an $83 \%$ criterion level, for 2 consecutive cays. A cue reversal was initiated upon completion of original learning. The positive stimulus was black, and the turtle had to achieve the $83 \%$ criterion for 2 days once again. This was followed by another reversal. In all, original training was followed by five reversal shifts.

\section{RESULTS AND DISCUSSION}

Extensive preliminary research with the red-eared slider and a pilot box turtle showed that these animals had a significant preference for black. Thus, white was chosen as the positive stimulus for original training. We attempted to run the pilot animal 30 trials a day and noted that the response latency increased from a maximum of $50 \mathrm{sec}$ over the first 15 trials to several minutes over the next 15 trials. Therefore, it was decided to run 12 trials per day, which facilitated the use of the Fellows' series (1967) in counterbalancing the position of the positive stimulus.

Trials and errors to criterion were recorded during training, as well as the subsequent reversals. The data to be reported reflect the inclusion of only. the first criterion day. The second criterion day was used to guarantee a level of stability in performance. Since the animal never fell below criterion after the first day, it was felt that the inclusion of the second day would merely serve to inflate the number of trials and errors.

The animal requred 96 trials to master the task during training, compared to $120,108,108,120$, and 168 from Reversal 1 to 5 , respectively. A Kolmorgorov-Smirnov was used to assess whether these data fit a hypothetical straight line. Such a fit would indicate no substantive change in trials to criterion from training through the last reversal. In fact, a significant departure from linearity was found $(D=.067, N=720, p<.01)$. Apparently, the departure occurred during the fifth reversal, where there was a dramatic increase in trials. This was accompanied by a tremendous increment in response latency, with the minimum latency at $180 \mathrm{sec}$. It was as if the animal were completely satiated on the task. From the standpoint of trials to criterion, then, the reversals did not seem to have much of an effect beyond producing apparent fatigue. This was confirmed by the error data.
The animal committed 44 errors during training, compared to $61,34,33,44$, and 63 from Reversal 1 to 5 , respectively. These data fit a straight line according to the Kolmorgorov-Smirnov ( $D=.059, N=279, p>.05$ ), indicating that there was essentially no change in errors from one phase of testing to the next.

An interesting behavior was noted. Vicarious trial and errors emerged beginning with Trial 40 of original learning. Upon approaching one stimulus, the animal turned and headed toward the opposite one. Double and triple alternations were not uncommon. In all, there were 18 such alternations during training, compared to $30.28,39,36$, and 43 during the subsequent reversal sessions. In this respect, the behavior of the turtle was very similar to that often observed in rodents and monkeys.

The turtle's behavior can be compared to that of the Mongolian gerbil, which has been tested under similar circumstances, using a similar criterion (Brosgole \& Ulatowski, 1973). The turtle required 6.6 times as many trials to reach criterion, compared to the gerbil, making 6.6 times as many errors. The difference in level between these animals was not the only one, however. Whereas, the gerbil was devastated by the first cue reversal, a learning set developed over four succeeding reversal shifts. On the other hand, the turtle seemed to be unaffected by successive cue reversals. Although this was very surprising, this one animal may not be at all represenative of the species. However, the important point is that the turtle was able to be shaped without having to resort to a water maze and food as a reinforcer.

\section{REFERENCES}

Borsgole, L., Sobrian, S. K., \& Contino, A. F. Out of the frying pan into the goalbox. Behavior Research Methods and Instrumentation, 1972, 4, 147-148.

Brosgole. L., \& Ulatowski, P. Heat training in the Mongolian gerbil. Psychological Reports, 1973, 33, 275-280.

Fellows, B. J. Change in stimulus sequences for discrimination tasks. Psychological Bulletin, 1967, 67, 87-92.

(Received for publication June 21, 1976.) 